\title{
BMJ Open Examining the relationship between poverty and length of stay: a repeated cross-sectional study of paediatric hospitalisations in Chile
}

\author{
Florencia Borrescio-Higa (D) ,' Dominiquo Santistevan ${ }^{2}$
}

To cite: Borrescio-Higa F, Santistevan D. Examining the relationship between poverty and length of stay: a repeated cross-sectional study of paediatric hospitalisations in Chile. BMJ Open 2020;10:e034512. doi:10.1136/ bmjopen-2019-034512

\section{- Prepublication history and} additional material for this paper are available online. To view these files, please visit the journal online (http://dx.doi org/10.1136/bmjopen-2019034512).

Received 23 September 2019 Revised 06 April 2020 Accepted 10 June 2020
Check for updates

(c) Author(s) (or their employer(s)) 2020. Re-use permitted under CC BY-NC. No commercial re-use. See rights and permissions. Published by BMJ.

${ }^{1}$ School of Government and GobLab, Universidad Adolfo Ibanez, Santiago, RM, Chile ${ }^{2}$ Department of Sociology, University of Chicago, Chicago, Illinois, USA

Correspondence to Dr Florencia Borrescio-Higa; florencia.borrescio@uai.cl

\section{ABSTRACT}

Objective To measure poverty-based disparities in inpatient length of stay for paediatric hospitalisations. In particular, this paper examines the relationship between municipality level poverty rates and length of stay, accounting for individual level characteristics.

Design We use patient discharge data to conduct a repeated cross-sectional study of the totality of paediatric hospitalisations in 15 regions of Chile, in the years 2011, 2013, 2015 and 2017.

Setting All hospital discharges in 15 regions of Chile. Participants 1033222 discharges for children under the age of 15, between 2011 and 2017.

Outcome measures Length of stay (LOS); LOS by type of insurance and type of hospital; hospitalisation rates; municipality-level average LOS.

Results We find that municipality level poverty rates are a significant predictor of LOS, even after controlling for individual and area level characteristics, including type of insurance. Children from municipalities in the poorest quintile have a LOS that is $14 \%$ shorter as compared with children from municipalities in the richest quintile. This relationship is stronger for publicly insured children: the decrease in LOS associated with the same poverty change is of $22 \%$.

Conclusions This paper shows that there is an association between municipality-level poverty rates and length of stay for paediatric hospitalisations in Chile. For the vast majority of the sample, and after controlling for individual level characteristics, an increase in the municipality level poverty rate is associated with a decrease in the length of stay. Further, there is a nonlinearity in the relationship, where at the highest poverty rates, poverty and LOS are positively associated. These findings are robust after controlling for type of hospital (public vs private), type of insurance (public vs private), type of diagnosis, as well as year and region fixed effects.

\section{INTRODUCTION}

It has long been recognised that social factors affect health outcomes, and the association between poverty and adverse health outcomes has also been extensively documented. ${ }^{2}$ There is a link between poverty and child well-being, and poor children have health disadvantages that may be exacerbated
Strengths and limitations of this study

- We used a large data set of 1033222 hospital discharges from all hospitals in Chile to study povertybased disparities in the utilisation of hospital care services.

- Individual patient-level data were used to estimate the effect of municipality level poverty rates on length of stay based on a fixed-effects estimation strategy.

- The study is limited in that the discharge data set does not allow to identify readmissions for individuals.

- Another limitation is that municipality level poverty data is only available on alternate years between 2011 and 2017

over time. ${ }^{3-7}$ Moreover, disparities in health outcomes are deeply related to disparities in the utilisation of healthcare services, with poor children less likely to be insured, less likely to have private insurance and having less access to and utilisation of care. ${ }^{8-10}$

In this paper, we analyse paediatric hospitalisations, using data from Chile. The average length of stay for adult hospitalisations (other than deliveries) in Chile is higher than the rest of the OECD (Organisation for Economic Co-operation and Development) countries, though there is no such comparison for paediatric hospitalisations. ${ }^{11}$ Not only is there large heterogeneity in length of stay across these countries, but the within country data also reveals a vast dispersion in length of stay.

The objective of this paper is to measure poverty-based disparities in inpatient length of stay (LOS) for paediatric hospitalisations, using data from Chile. In particular, we examine whether children from municipalities with high poverty rates have different LOS compared with children from municipalities with low poverty rates, even after 
controlling for individual level characteristics such as insurance status.

While ideally one would have the full set of characteristics of the patients, insurance status is the best source of socioeconomic information available in the data. We start the analyses with the distinction of private and public insurance in order to understand if, within a single insurance scheme, poverty rates are relevant in explaining LOS.

There are several reasons why one might anticipate different lengths of stay for children from poorer areas, though the sign of the correlation between poverty and LOS is not clear. On one hand, insurance generosity is positively related with utilisation, and relatedly, parents with more generous insurance schemes may be more willing to accept longer stays. ${ }^{12}$

On the other hand, children from poorer areas are more likely to come from families with lower income and education (factors that are associated with poorer health), and are also more likely to delay care, and may therefore have a worse health status overall, which may require longer stays once hospitalised. ${ }^{10}$ Further, the reality of many public hospitals is that they are often unable to meet demand, thus creating long waiting lists, and may have to respond to demand with higher bed turnover rates. ${ }^{13} 14$ Therefore, the question of the relationship between poverty and LOS remains one to be addressed empirically.

\section{Background}

Chile has a mixed, non-complementary public-private healthcare system, where workers have to choose between the National Health Fund, or one of several private insurers, for their mandatory contributions.

About 75 per cent of the population is covered by public insurance, while only 18 per cent has private insurance, which in total covers 92 per cent of the population. Only 2.7 per cent of the population lacks insurance, and the rest are covered by other smaller special insurance schemes, such as those belonging to the police or armed forces. Those with private insurance are on average wealthier than their publicly insured counterparts. ${ }^{15}$

There are four tiers within the public insurance system: the lower tier covers those with no income, free of charge and free of copayments. The next tier covers those below the minimum wage, with a contribution of their salary but no copayments. The following two tiers make the same percentage contribution from their salary, but face copayments that increase with their income, of 10 and 20 per cent, respectively. Except for the lowest tier, individuals can opt to receive care at a network of private facilities through an additional copayment for each service. ${ }^{16}$

\section{DATA}

The main source of data is the administrative records from the Ministry of Health, comprised of the universe of hospital discharges in Chile for the years 2011, 2013,
2015 and $2017 .{ }^{17}$ Though this data is available for other years, we restrict it to these 4 years in order to match the data with municipality level poverty rate data. The sample includes information on the age of the patient, diagnosis code (International Classification of Diseases, $10^{\text {th }}$ Revision (ICD-10)), length of stay, type of insurance, type of institution and municipality of residence. The data set does not, however, allow for patients to be tracked across hospitalisation events, and therefore it is not possible to identify readmissions. We use the diagnosis code to create an indicator variable for paediatric complex chronic conditions. ${ }^{18}$

There are 1056308 hospital discharges for children under the age of 15 in the initial data set from the years 2011, 2013, 2015 and 2017. We drop observations for which we cannot identify the type of hospital $(0.45 \%$ of all cases). The main outcome of interest is the length of stay (henceforth LOS), which is measured as the number of days a patient stayed in the hospital. We apply an outlier bound of two SDs to the mean of LOS. ${ }^{19}$ We also apply alternative definitions of outlier bounds to show that results are robust to these changes in the online supplementary appendix. After removing entries where the length of stay is outside of our calculated boundary of 41.8 days, we have 1033222 observations in our sample, with an average of approximately 258305 observations per year. We finally apply a logarithmic transformation to get our main outcome measure: $\log L O S$.

There are 339 municipalities across 15 regions in Chile represented in our final data. For each municipality, we define an indicator variable that is equal to 1 if the municipality is rural and 0 otherwise. Each discharge in the sample is then matched with municipality of residence poverty level rates for a given year. ${ }^{20}$ Poverty rates at this disaggregated level are reported every other year by the Ministry of Social Development based on the continuous household survey CASEN. ${ }^{21}$ We finally apply a second order transformation to the poverty rates to arrive at the main explanatory variables: poverty and poverty_sq.

\section{METHODS \\ Analysis}

The empirical strategy is based on a fixed effects model that exploits the within-region variation to explain how changes in poverty are associated with changes in LOS. Fixed effect models allow adjustment for unobserved time-invariant confounders. In particular, the inclusion of region (municipality) fixed-effects eliminates any unobservable time-invariant region (municipality) characteristics correlated with region (municipality) poverty rates or LOS.

We perform regression analyses for the logarithm of the length of stay $(\log L O S)$ using the municipality poverty rate (poverty), its quadratic (poverty_sq) and a series of explanatory variables. The latter include: an indicator variable for female, age and its quadratic polynomial, an indicator for public insurance, an indicator for public hospital, an 
indicator for paediatric complex chronic conditions and an indicator for rural municipality. To control for time invariant geographical and socioeconomic characteristics as well as time trends, we include the patient's region of residence fixed effects and year fixed effects.

The main equation is of the form:

$\log L O S_{i m t}=\beta_{0}+\beta_{1}$ poverty $_{i m t}+\beta_{2}$ poverty_sq $_{i m t}+\beta_{3} X_{i m t}+\gamma_{r}+\delta_{t}+\varepsilon_{i m t}$

for an individual discharge $i$, in municipality $m$ and region $r$, and year $t$.

We perform different specifications of the regression above, restricting the sample to discharges that are publicly insured, privately insured, from public hospitals and from private hospitals each separately. Further, we analyse the case of the patients with public insurance who are hospitalised at public institutions separately, with the aim of holding reimbursement schemes constant.

All fixed effects models are estimated assuming a loglinear model through ordinary least squares. Since the main outcome variable (LOS) is of logarithmic form, the effect of poverty on LOS can be interpreted as the per cent change in length of stay that is associated with a one-point change in the poverty rate, according to the following formula: $\left[\hat{\beta}_{1}+2 \hat{\beta}_{2}\right.$ poverty $]$, where $\hat{\beta}_{1}$ is the estimated coefficient for poverty level and $\hat{\beta}_{2}$ is the estimated coefficient for the square of poverty, at each poverty level. Note that this specification allows for a different sign of the relationship at different levels of poverty.

SEs are robust to heteroscedasticity and clustered at the area level, since individuals within a region may be correlated. We also apply an alternative level of cluster to the SEs to show that results are robust to these changes in the online supplementary appendix.

Two additional, more restrictive specifications include municipality fixed effects in the full sample and in the public insurance sample, to account for unobserved fixed differences across municipalities. This specification renders more support to the main analysis, as the municipality fixed effects strategy allows to control for municipality-specific characteristics (such as environmental factors) which are correlated with poverty and can affect utilisation. Therefore, this fixed-effects model exploits the within-municipality variation over time to estimate how changes in poverty are associated with changes in LOS.

To address a potential concern that children from poorer areas may be hospitalised more frequently but for potentially less serious reasons, we create a subsample of discharges for which there are over 1000 observations for a single diagnosis code, which accounts for $68 \%$ of the total sample. Note that 1000 is an arbitrarily high number of observations, but results do not depend on the threshold that is chosen. For this sample, we replicate the main analysis adding the diagnosis as a control, which implies that in this specification we are comparing children with the same ICD code as a diagnosis (and controlling for all of the other variables), and testing whether poverty rates have explanatory power over the LOS.
We then aggregate the discharge data to the municipality level to analyse the relationship between hospitalisation rates and poverty rates, in order to analyse whether children from poorer municipalities are hospitalised more often than their counterparts from richer municipalities.

Using the aggregated discharge data, we finally proceed to restricting the sample to the Metropolitan Area of Santiago (the biggest and most densely populated region, home to $40.6 \%$ of the total population ${ }^{22}$ ), to analyse the geographical variation of the relationship between average length of stay and poverty rates, and present unadjusted comparisons of average length of stay for publicly insured patients.

\section{Patient and public involvement}

Neither patients nor the public were involved in this study.

\section{RESULTS}

Table 1 presents descriptive statistics of the main variables under analysis. The vast majority of discharges correspond to children with public insurance $(74.6 \%)$ and from a public hospital (72.3\%). Both categories present a decrease over time. About $43.7 \%$ of discharges correspond to girls, and the mean age is 4.2 . The average length of stay is 3.96 days, and is fairly stable over the years. The overall mean poverty rate is $15.7 \%$, though it decreased from $23 \%$ to $12 \%$ in the period under analysis. Across the 7 -year period, the poorest $20 \%$ of the sample live in a municipality with an average poverty rate of almost $30 \%$, while the richest quintile live in municipalities with an average poverty rate of $5.5 \%$.

Column (1) in table 2 shows estimates of a fixed effects regression model explaining the log of length of stay on the poverty rate and its quadratic, individual level controls, type of hospital, a rural municipality indicator and region and year of fixed effects. The regional fixed effects are jointly significant, so that the model relies on within-region variation across municipalities and over time to estimate the relationship between poverty rates and LOS. We find that the coefficient on the poverty variable is negative and statistically significant at the 1 per cent level (beta_pov $=-0.007$, CI -0.008 to -0.006 ), as is the coefficient on poverty_sq, the square of poverty level (beta_pov2=0.0001, CI 0.00007 to 0.00014 ).

Note that the poverty rate is still significant even after controlling for the individual's type of insurance. The coefficients indicate that a 10-point increase in poverty rates (calculated from the lowest poverty quintile rate of $5.5)$ is associated with a $6 \%$ average decrease in length of stay.

Note that this 10-point increase in poverty rates is equivalent of moving from the lowest quintile poverty rate of 5.5 to the average poverty rate. Further, a change in poverty rates from the lowest poverty quintile (5.5) to the highest one (29.5) is associated with a $14 \%$ decrease in LOS. Columns (2) and (3) restrict the sample to 
Table 1 Descriptive statistics

\begin{tabular}{|c|c|c|c|c|c|c|}
\hline & \multicolumn{2}{|c|}{ Full sample } & \multirow{2}{*}{$\begin{array}{l}2011 \\
\text { Mean }\end{array}$} & \multirow{2}{*}{$\begin{array}{l}2013 \\
\text { Mean }\end{array}$} & \multirow{2}{*}{$\begin{array}{l}2015 \\
\text { Mean }\end{array}$} & \multirow{2}{*}{$\begin{array}{l}2017 \\
\text { Mean }\end{array}$} \\
\hline & Mean & SD & & & & \\
\hline LOS & 3.96 & 5.22 & 3.79 & 4.23 & 3.94 & 3.90 \\
\hline Public insurance & 0.75 & 0.44 & 0.78 & 0.74 & 0.73 & 0.74 \\
\hline Public hospital & 0.72 & 0.45 & 0.76 & 0.72 & 0.70 & 0.71 \\
\hline Age & 4.24 & 4.54 & 4.22 & 4.22 & 4.20 & 4.30 \\
\hline Female indicator & 0.44 & 0.50 & 0.44 & 0.43 & 0.44 & 0.44 \\
\hline Medical complexity indicator & 0.02 & 0.12 & 0.01 & 0.01 & 0.02 & 0.02 \\
\hline Rural municipality & 0.20 & 0.40 & 0.21 & 0.21 & 0.19 & 0.19 \\
\hline Poverty rate & 15.69 & 10.18 & 23.07 & 14.98 & 11.90 & 11.87 \\
\hline \multicolumn{7}{|l|}{ Poverty rate by quintile: } \\
\hline Low & 5.49 & 3.33 & 9.34 & 4.39 & 3.96 & 3.94 \\
\hline Low medium & 10.47 & 4.04 & 16.44 & 9.79 & 7.48 & 7.47 \\
\hline Medium & 14.61 & 4.80 & 21.81 & 14.35 & 10.57 & 10.60 \\
\hline High medium & 18.81 & 5.54 & 27.02 & 17.92 & 14.41 & 14.38 \\
\hline High & 29.54 & 10.26 & 41.54 & 29.13 & 23.30 & 23.26 \\
\hline Observations & \multicolumn{2}{|c|}{1033222} & 279586 & 259758 & 254507 & 239371 \\
\hline
\end{tabular}

Notes: authors' calculations from patient discharge data.

LOS, length of stay.

discharges for children covered by public and private insurance, respectively. Column (2) reveals that the main effect is driven by publicly insured hospitalisations. That is, for a child with public insurance, living in a poorer municipality is associated with a decreased the length of stay (beta_pov $=-0.011$, CI -0.016 to -0.0056 ; beta pov2 $=0.00016$, CI 0.00005 to 0.0003 ). The coefficients indicate that a change in poverty rates from the lowest poverty quintile to the highest one, is associated with a $20 \%$ decrease in length of stay on average. Note that for privately insured hospitalisations, municipality level poverty rates are positively associated with LOS (beta pov $=0.005$, CI 0.0015 to 0.0086 ; beta_pov $2=-0.00007$, CI -0.00015 to 0.000005 ).

Restricting the sample to discharges from public and private hospitals, respectively, Column (4) shows that the effect of poverty rates operates when discharges are from public hospitals, which represent $73 \%$ of all discharges (beta_pov $=-0.0067$, CI -0.0096 to -0.0036 ; beta_pov2 $=0.00009$, CI 0.00004 to 0.0001$)$. On the other hand, when the hospitalisation occurs at a private institution (column 5), the magnitude of effect of poverty rates

\begin{tabular}{|c|c|c|c|c|c|c|}
\hline $\begin{array}{l}\text { Dependent } \\
\text { variable: log LOS }\end{array}$ & $\begin{array}{l}\text { Full } \\
\text { sample } \\
\text { (1) }\end{array}$ & $\begin{array}{l}\text { Public } \\
\text { insurance } \\
\text { (2) }\end{array}$ & $\begin{array}{l}\text { Private } \\
\text { insurance } \\
\text { (3) }\end{array}$ & $\begin{array}{l}\text { Public } \\
\text { hospital } \\
\text { (4) }\end{array}$ & $\begin{array}{l}\text { Private } \\
\text { hospital } \\
\text { (5) }\end{array}$ & $\begin{array}{l}\text { Public insurance at } \\
\text { public hospital } \\
\text { (6) }\end{array}$ \\
\hline Poverty rate & $\begin{array}{l}-0.0070^{\star \star \star} \\
(0.0006)\end{array}$ & $\begin{array}{l}-0.0108^{\star \star \star} \\
(0.0024)\end{array}$ & $\begin{array}{l}0.0051^{\star \star \star} \\
(0.0016)\end{array}$ & $\begin{array}{l}-0.0067^{\star \star \star} \\
(0.0014)\end{array}$ & $\begin{array}{l}0.0027^{\star \star \star} \\
(0.0009)\end{array}$ & $\begin{array}{l}-0.0072^{\star \star \star} \\
(0.0012)\end{array}$ \\
\hline Poverty rate squared & $\begin{array}{l}0.0001^{\star \star \star} \\
(0.0000)\end{array}$ & $\begin{array}{l}0.0002^{\star \star \star} \\
(0.0000)\end{array}$ & $\begin{array}{l}-0.0001^{*} \\
(0.0000)\end{array}$ & $\begin{array}{l}0.0001^{\star \star \star} \\
(0.0000)\end{array}$ & $\begin{array}{l}-0.0000^{*} \\
(0.0000)\end{array}$ & $\begin{array}{l}0.0001^{* \star *} \\
(0.0000)\end{array}$ \\
\hline Public insurance indicator & $\begin{array}{l}0.0002 \\
(0.0286)\end{array}$ & & & $\begin{array}{l}0.1305^{\star \star \star} \\
(0.0126)\end{array}$ & $\begin{array}{l}-0.0929^{*} \\
(0.0521)\end{array}$ & \\
\hline Public hospital indicator & $\begin{array}{l}0.3776^{\star \star \star} \\
(0.0840)\end{array}$ & $\begin{array}{l}0.4759^{\star \star \star} \\
(0.1024)\end{array}$ & $\begin{array}{l}0.2009^{\star \star *} \\
(0.0623)\end{array}$ & & & \\
\hline Observations & 1033222 & 770890 & 262332 & 746639 & 286583 & 695929 \\
\hline
\end{tabular}

Notes: All regressions include the following controls: age, age squared, an indicator for female, an indicator for medical complexity condition, indicator for rural municipality, year and regional fixed effects. SEs are clustered at the regional level.

${ }^{* \star *} p<0.01,{ }^{* *} p<0.05,{ }^{*} p<0.1$

log LOS, logarithm of the length of stay. 


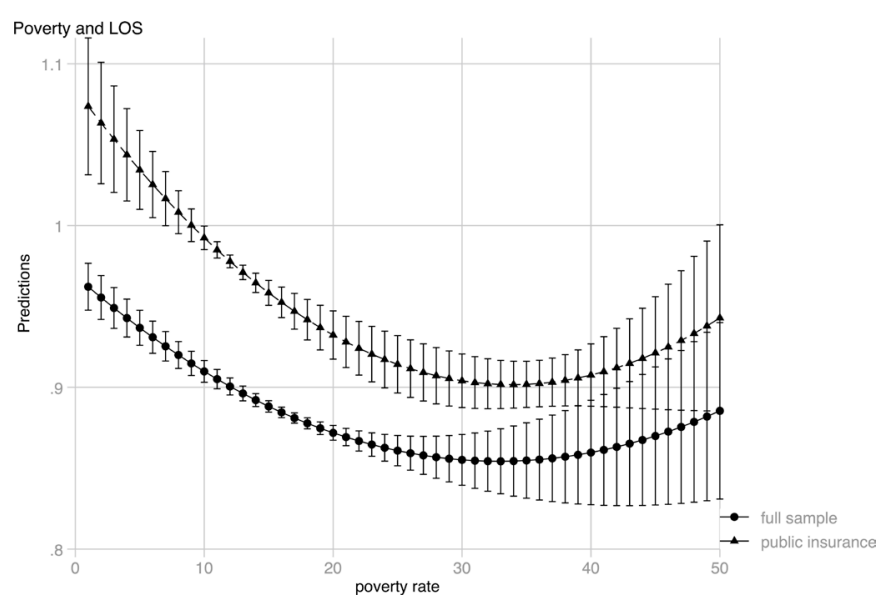

Figure 1 Poverty rates and LOS prediction. LOS, length of stay.

is smaller, and with the opposite sign. Again, these results hold even after controlling for type of insurance.

Column (6) shows that for the sample of discharges from public hospitals that are publicly financed (which hold reimbursement schemes constant), the effect of poverty rates on LOS is almost identical to the effect in the full sample (beta_pov $=-0.007$, CI -0.009 to -0.005 ; beta_pov2 $=0.0001$, CI 0.00005 to 0.00016 ).

Figure 1 illustrates the relationship between poverty rates and LOS by plotting the predicted values of the regressions for all discharges, and for discharges for patients with public insurance. The turning point of the relationship is 32.9 for the whole sample and 33.9 for the public insurance sample, implying that for poverty levels below these thresholds, an increase in poverty rates implies a decrease in LOS, while at higher poverty levels, the association becomes positive. Note that the estimates are more precise in the negatively sloped part of the curve, as the overwhelming majority of discharges correspond to children living in municipalities with poverty rates under the threshold.

Online supplementary appendix table 1 presents a series of robustness checks for the main results shown above. We control for tiers of public insurance coverage (though they are individually non-significant, they are jointly significant). We then replicate the main analysis with a different definition for the bound in length of stay (three SDs to the mean of LOS) ${ }^{19}$ Further, online supplementary appendix table 2 presents another set of robustness checks, where we replicate the main analysis with SEs clustered at the hospital level (instead of at the same level as the area fixed effects). In all cases, we find that the main results are robust to these changes in specification.

Table 3 presents the results for the LOS where we include municipality level fixed effects to control for any time invariant characteristics at the municipality level. Column (1) shows that the poverty rates are negatively associated with the length of stay (beta_pov $=-0.0072$, CI -0.0121 to -0.0023 ; beta_pov2 $=0.0001$, CI 0.0006 to $0.0002)$, particularly for children with public insurance, (as shown in column (2), beta_pov $=-0.0095$, CI -0.016 to -0.0028 ; beta_pov2 $=0.00016$, CI 0.000069 to 0.00026 ). Column (3) presents the analysis based on the sample with over 1000 observations for each diagnosis, so that it is possible to add the diagnosis code as a control, and once more we find that the coefficients on poverty rates are almost identical to the previous coefficients (beta pov $=-0.00705$, CI -0.0085 to -0.0056 ; beta_pov2 $=0.0001$, CI 0.00006 to 0.00014). Finally, column (4) presents results on the aggregate analysis of hospitalisation rates to find that children from poorer municipalities are less likely to be hospitalised (beta_pov $=-1.029$, CI -1.739 to -0.318 ; beta_pov2 $=0.0109$, CI 0.0002 to 0.0218 ) .

Figure 2 presents the spatial distribution of: (i) poverty rates and (ii) (unadjusted) average LOS for patients with

Table 3 Fixed effects models for poverty, LOS and hospitalisation rates

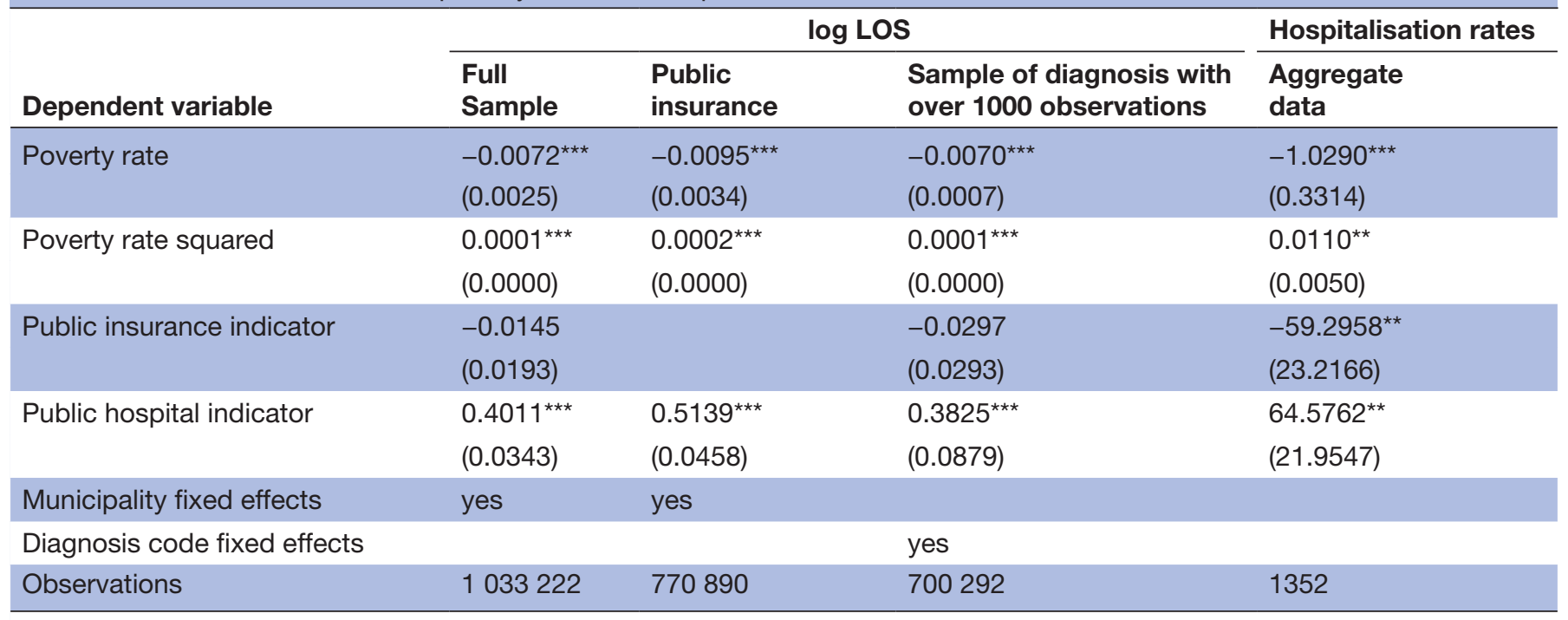

${ }^{* * *} \mathrm{p}<0.01,{ }^{* *} \mathrm{p}<0.05,{ }^{*} \mathrm{p}<0.1$

log LOS, logarithm of the length of stay; LOS, length of stay. 

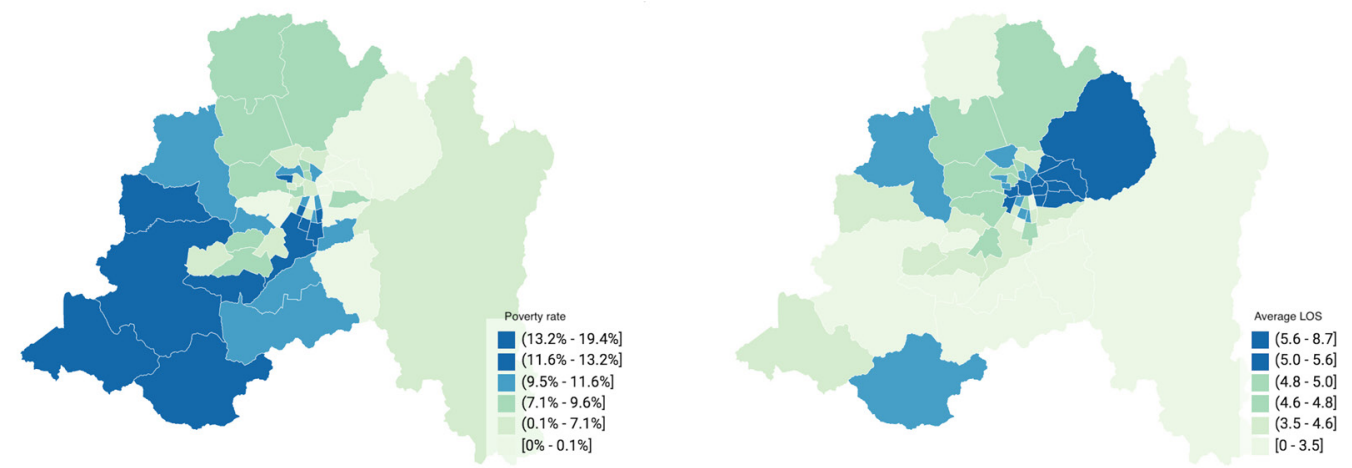

Figure 2 Poverty rates and average LOS. Notes: The map on the left shows average poverty rates for municipalities in the metropolitan region. The map on the right shows average LOS of the same municipalities (unadjusted). LOS, length of stay.

public insurance, for the case of the Region Metropolitana (the region home to the capital city of Chile). These maps show a negative association between poverty rates and average length of stay for children with public insurance (beta:-0.08, CI: -0.15 to -0.06) (unadjusted, data not shown). For this sample, a publicly insured child will have a stay that is on average 0.8 days shorter if they come from a municipality at the national average of poverty level in our sample (15.7), as compared with a municipality in the lowest quintile of poverty levels (5.5).

\section{DISCUSSION}

In this paper we analyse poverty-based disparities in length of stay for paediatric hospitalisations in Chile. We find that, for the vast majority of the sample, children living in municipalities with higher poverty rates have shorter hospital stays, even after controlling for type of insurance and type of hospital. Specifically, discharges for children from a municipality in the poorest quintile have LOS that are $14 \%$ shorter, as compared with children from municipalities in the richest quintile. For a child with public insurance, the magnitude of this association is $22 \%$. Interestingly, at the highest levels of poverty, the relationship between poverty rates and LOS becomes positive.

Results should be interpreted with the understanding that the main limitation of this study is that the data does not allow for tracking individuals across discharges, and therefore we are not able to account for readmission incidents. Our estimations, however, rely on a large sample size (over one million observations), which accounts for the totality of hospital discharges in Chile for the years 2011, 2013, 2015 and 2017.

While most research on health disparities is focussed on adults from developed countries, the evidence on child health disparities across socioeconomic status is relatively scarce. ${ }^{2}$ Alexander and Currie show that hospitals are less likely to admit children with public insurance compared with privately insured children, particularly during peak occupation weeks. ${ }^{10}$ Using data for one US county, Beck $e t$ al build a measure that adds up the total number of hospitalisation days per 1000 children in a county and find that poorer communities disproportionately bear the burden of paediatric hospital stays. ${ }^{23}$ However, this measure comprises the extensive and the intensive margin in utilisation, which are the probability of being hospitalised, and the number of days in the hospital, respectively. Our analysis is focussed on the intensive margin, that is: once a child is hospitalised, what is the level of care received, as measured by LOS.

In the case of Chile, a study shows differences in mortality by type of hospital ownership, which in turn is related to an individual's socioeconomic characteristics, though the latter are not explicitly incorporated in the estimations. ${ }^{24}$ Other evidence points to a non-linear relationship between income and self-perceived oral health. ${ }^{25}$ There is also some evidence on healthcare utilisation (but not LOS), with higher utilisation for general practitioners and physician visits among richer adults, while emergency room visits and hospitalisations are concentrated among lower-income quintiles. ${ }^{26}$ Although these studies highlight inequalities in the perception and utilisation of health services, they rely on survey data and are focussed on the adult population. To our knowledge, this is the first study to show disparities in LOS among children in Chile.

Why do children from poorer municipalities have shorter stays in hospitals (even stratifying by type of hospital or type of insurance)? There are several potential explanations. First, there is evidence of long waiting lists among publicly insured, mostly poorer patients. ${ }^{14} 27$ This is linked to capacity or operational constraints that put pressure on available resources at public institutions in or near poor municipalities that focus their attention on poor families. This higher pressure may have some effect on the length of stay because hospitals respond to demand with higher bed turnover rates. Because the data set does not allow to link individuals across hospital discharges, we are not able to assess whether too short of a stay increases the chance of a new admission, though some evidence suggests that shorter paediatric stays do not increase the chance of readmission. ${ }^{28}$

Further, it is likely that families with public insurance and with higher income may be able to purchase the option of care at a private institution and avoid the 
waiting time, which had a median of 391 days for an adult elective surgery in 2017. ${ }^{27} 29$ Relatedly, parents with more generous insurance schemes may be more willing to accept longer stays, as they are more likely to have higher levels of healthcare utilisation overall. ${ }^{12}$ This is consistent with our result that privately insured patients from richer municipalities have longer stays.

One key finding of this paper is the non-linearity in the association between poverty and LOS. While for the most part as poverty increases, a lower LOS is observed, at the highest poverty levels, we observe that the relationship becomes positive.

We argue that there are two mechanisms operating in this relationship, and that they become more or less relevant at different levels of the poverty distribution. For the majority of the sample, with poverty levels below 33 per cent, it is most likely the operational constraint on public hospitals becomes more relevant as poverty levels increase, as suggested by the waiting lists being concentrated on the second tier of public insurance. ${ }^{27}$ At the highest poverty levels (above 33 per cent), where the poor and indigent are concentrated, presumably the income-health gradient becomes more relevant and children have worse health status overall, which may require longer stays once hospitalised.

Since not only do children from poor municipalities have shorter LOS, but they are also less likely to be hospitalised, these results are consistent with an underprovision of hospital care for the poorer municipalities. These findings point to a disparity in the utilisation of healthcare services, and reveal a need for deeper investigation into how publicly insured poor patients access health services. Future research will look at hospital capacity and the utilisation of primary care services, and explore how, and if, the social disadvantages translate into health disadvantages.

\section{CONCLUSION}

This paper shows that there is an association between municipality-level poverty rates and length of stay for paediatric hospitalisations in Chile. For the vast majority of the sample, an increase in the municipality level poverty rate is associated with a decrease in the length of stay, even after controlling for individual level characteristics. This disparity persists within a single insurance scheme: among publicly insured children, and even among children with public insurance who are hospitalised at public institutions. Further, there is a non-linearity in the relationship, where at the highest poverty rates, poverty and LOS are positively associated.

Acknowledgements The data set used in the analysis is anonymised and therefore no ethical approval was required. There was no patient involvement.

Contributors FBH and DS were responsible for the study design, data collection, literature review, data analysis and drafted the manuscript. Both authors had full access to all of the data (including statistical reports and tables) in the study and can take responsibility for the integrity of the data and the accuracy of the data analysis.
Funding FBH is supported by grant 11160513 of PROYECTO FONDECYT Iniciacion from CONICYT in Chile. The content is solely the responsibility of the authors and does not necessarily represent the official views or policies of CONICYT. FBH gratefully acknowledges financial support from the Office of Institutional Research at Universidad Adolfo Ibañez. The funders did not play a role in the design and conduct of the study, in the collection, analysis and interpretation of the data, and in the preparation, review or approval of the manuscript.

Map disclaimer The depiction of boundaries on this map does not imply the expression of any opinion whatsoever on the part of BMJ (or any member of its group) concerning the legal status of any country, territory, jurisdiction or area or of its authorities. This map is provided without any warranty of any kind, either express or implied.

Competing interests None declared.

Patient and public involvement Patients and/or the public were not involved in the design, or conduct, or reporting, or dissemination plans of this research.

Patient consent for publication Not required.

Provenance and peer review Not commissioned; externally peer reviewed.

Data availability statement Data are available in a public, open access repository. Data sharing: patient level hospital discharge data is anonymised and is available at http://www.deis.cl/descargar-bases-de-datos/ with open access (registration required). Statistical codes are available from the corresponding author upon request.

Open access This is an open access article distributed in accordance with the Creative Commons Attribution Non Commercial (CC BY-NC 4.0) license, which permits others to distribute, remix, adapt, build upon this work non-commercially, and license their derivative works on different terms, provided the original work is properly cited, appropriate credit is given, any changes made indicated, and the use is non-commercial. See: http://creativecommons.org/licenses/by-nc/4.0/.

ORCID iD

Florencia Borrescio-Higa http://orcid.org/0000-0001-7521-9750

\section{REFERENCES}

1 Adler NE, Rehkopf DH. U.S. disparities in health: descriptions, causes, and mechanisms. Annu Rev Public Health 2008;29:235-52.

2 Ridgeway JL, Wang Z, Finney Rutten LJ, et al. Conceptualising paediatric health disparities: a metanarrative systematic review and unified conceptual framework. BMJ Open 2017;7:e015456:1-9.

3 Chaudry A, Wimer C. Poverty is not just an indicator: the relationship between income, poverty, and child well-being. Acad Pediatr 2016;16:S23-9.

4 Aizer A, Currie J. Disadvantage and health at birth. Science 2014;344:856-61.

5 Fitzsimons E, Goodman A, Kelly E, et al. Poverty dynamics and parental mental health: determinants of childhood mental health in the UK. Soc Sci Med 2017;175:43-51.

6 Drewnowski A, Rehm C, Kao C, et al. Poverty and childhood overweight in California assembly districts. Health Place 2009;15:631-5.

7 Liu SR, Kia-Keating M, Santacrose DE, et al. Linking profiles of neighborhood elements to health and related outcomes among children across the United States. Health Place 2018;53:203-9.

8 Selden TM, Hudson JL. Access to care and utilization among children: estimating the effects of public and private coverage. Medical Care 2006;44:19-26.

9 Dafny L, Gruber J. Public insurance and child hospitalizations: access and efficiency effects. J Public Econ 2005;89:109-29.

10 Alexander D, Currie J. Are publicly insured children less likely to be admitted to hospital than the privately insured (and does it matter)? Econ Hum Biol 2017;25:33-51.

11 OECD. Average length of stay in hospitals. In: Health at a Glance 2017: OECD Indicators. Paris: OECD Publishing, 2017: 176-8.

12 Einav L, Finkelstein A. Moral hazard in health insurance: what we know and how we know it. J Eur Econ Assoc 2018;16:957-82.

13 Subsecretaría de Redes Asistenciales, Ministerio de Salud. GLOSA 06: Lista de espera GES Y no GES, 2017. Available: http://web. minsal.cl/wp-content/uploads/2018/01/glosa-06_noviembre_2017. pdf

14 Bedregal P, Ferrer JC, Figueroa B, et al. La Espera En El Sistema de Salud Chileno: Una Oportunidad Para Poner a Las Personas Al Centro. 12, 2017. https://politicaspublicas.uc.cl/wp-content// uploads/2017/12/propuestas_listas_espera.pdf 
15 CASEN. Resultados Salud CASEN 2011, 2012. Available: http:// observatorio.ministeriodesarrollosocial.gob.cl/layout/doc/casen/ 2013_03_27_Salud_CASEN_2011.pdf

16 Fonasa. Fondo Nacional de Salud. Available: https://www.fonasa.cl/ sites/fonasa/beneficiarios/informacion-general

17 DEIS - Ministerio de Salud de Chile. Bases de Datos Egresos Hospitalarios. Available: http://www.deis.cl/bases-de-datos-egresoshospitalarios/

18 Feudtner C, Christakis DA, Connell FA. Pediatric deaths attributable to complex chronic conditions: a population-based study of Washington state, 1980-1997. Pediatrics 2000;106:205-9.

19 Felder S. The variance of length of stay and the optimal DRG outlier payments. Int J Health Care Finance Econ 2009;9:279-89.

20 Ministerio de Desarrollo Social y Familia de Chile. Estimaciones de Pobreza Comunal.

21 Ministerio de Desarrollo Social. Encuesta de Caracterización Socioeconómica Nacional -CASEN. Available: http://observatorio. ministeriodesarrollosocial.gob.cl/casen-multidimensional/casen/ basedatos.php

22 Instituto Nacional de Estadísticas de Chile (INE). Compendio Estadístico ine 2015, 2015.
23 Beck AF, Riley CL, Taylor SC, et al. Pervasive income-based disparities in inpatient bed-day rates across conditions and subspecialties. Health Aff 2018;37:551-9.

24 Cid Pedraza C, Herrera CA, Prieto Toledo L, et al. Mortality outcomes in hospitals with public, private not-for-profit and private for-profit ownership in Chile 2001-2010. Health Policy Plan 2015;30 Suppl 1:i75-81.

25 Gallego F, Larroulet C, Palomer L, et al. Socioeconomic inequalities in self-perceived oral health among adults in Chile. Int J Equity Health 2017;16:1-13.

26 Vásquez F, Paraje G, Estay M. Income-related inequality in health and health care utilization in Chile, 2000 - 2009. Revista Panamericana de Salud Pública 2013;33:98-106.

27 Ministerio de Salud de Chile. Glosa 06: Lista de Espera no GES Y Garantías de Oportunidad GES Retrasadas. Santiago, 2017.

28 Morse RB, Hall M, Fieldston ES, et al. Children's hospitals with shorter lengths of stay do not have higher readmission rates. $J$ Pediatr 2013;163:1034-8.

29 Cuadrado NC, Crispi Galleguillos F, Estay Miquel R, et al. Desde El Conflicto de las Listas de Espera, Hacia El Fortalecimiento de Los Prestadores Públicos de Salud. Una Propuesta para Chile, 2017. 